\title{
Polycyclic aromatic hydrocarbons in the firefighter workplace: The results from the first in Poland short-term measuring campaign
}

\author{
Wioletta Rogula-Kozłowska ${ }^{1, *}$, Małgorzata Majder-Łopatka1 , Izabela Jureczko², \\ Matgorzata Ciuka-Witrylak ${ }^{1}$ and Aneta Lukaszek-Chmielewska ${ }^{1}$ \\ ${ }^{1}$ The Main School of Fire Service, Faculty of Fire Safety Engineering, 52/54 Słowackiego St., 01-629 \\ Warsaw, Poland \\ ${ }^{2}$ Power Research \& Testing Company "ENERGOPOMIAR" Ltd., gen. J. Sowińskiego 3 St., 44-100 \\ Gliwice, Poland
}

\begin{abstract}
The results of investigations into 15 ambient polycyclic aromatic hydrocarbons at two Polish fire stations belonging to the National Fire Service are presented. At each station, on five different days, hydrocarbons were sampled simultaneously in the changing room, garage, and exterior of the station (in the atmospheric air). The indoor and outdoor diagnostic ratios and benzo(a)pyrene carcinogenicity equivalents were computed from the measured concentrations. The former indicated the combustion of various materials and fuels as the hydrocarbons source, the latter expressed the cumulative carcinogenic hazard from the hydrocarbon mixture. Naphthalene and acenaphthene had the greatest ambient concentrations at each site. The greatest summary concentrations of the 15 hydrocarbons occurred in the changing rooms.
\end{abstract}

\section{Introduction}

Since the early 1980s in the United States, and since the beginning of the 21th century in other countries, the firefighter occupational health hazard has been comprehensively studied not only as direct endangerment of life and health in a firefighting situation, but also as a hazard from exposure to hazardous substances, which are often carcinogenic [110]. Despite the use of personal protection equipment, the danger of exposure of a firefighter to extremely high concentrations of toxic substances is great, and although its duration is usually short, it can be very intense and occur many times in the career of a firefighter. However, the cumulative health effects of such multiple acute exposures are hard to trace back to their causes, usually distant in the past and not recorded.

Smoke emitted by a fire contains carcinogens [11-15]. From among the polycyclic aromatic hydrocarbons (PAHs) released into the air in vast amounts during a fire, are benzo[a]pyrene, which is carcinogenic to humans, dibenz[a,h]anthracene which is most likely carcinogenic, and benz[a]anthracene, benzo[b]fluoranthene, benzo[j]fluoranthene,

*Corresponding author: wrogula@sgsp.edu.pl 
benzo[k]fluoranthene, chrysene, indeno[1, 2, 3-c,d]pyrene, and naphthalene which are possibly carcinogenic $[16,17]$. Although direct contact with these PAHs and the presence of their metabolites in the organisms of firefighters taking part in firefighting has been proved [e.g. 6, 7, 10], the linkage of lung cancer incidence among firefighters with their occupation was considered as inconclusively proven for quite a long time [16, 17]; and only lately and cautiously, the lung cancer incidence rate among career firefighters was considered essentially higher than in the normal population [4, 5, 18-31].

A firefighter can be exposed to very high concentrations of various products of combustion and pyrolysis, including PAHs both in its gaseous phase and adsorbed on ambient particulate matter (PM-bound) not only during firefighting operations and training, but also afterwards as a result of contact with contaminated protective gear. Firefighting gear can be contaminated with combustion products whose later off-gassing can result in inhalation exposure [23]. Some volatile organic compounds, generated during controlled structure burns, can later be off-gassed by the firefighters' protective gear and be absorbed and exhaled in their breath [5, 24, 25]. Benzene and some PAHs, despite turnout gear, most likely enter firefighters' bodies through their skin. PAHs can be absorbed dermally during firefighting or inhaled during the doffing of gear that hass off-gassing contaminants $[5,26]$. However, even the application of cleansing wipes to PAH contaminated skin can be ineffective [27]. Therefore PAHs, mainly gaseous, contaminate firefighter turnout gear and skin and are off-gassed later in the fire truck cab and in the fire station [28]. They contribute to the occupational health hazard for firefighters on duty when they are not fighting a fire and can have long-term health effects.

The goal of the work was to determine the ambient concentrations of selected gaseous PAHs in two rooms of a fire station staffed by career firefighters, a garage and changing room, and compare them with the outdoor concentrations of these PAHs.

\section{Experimental}

Both fire stations of interest, one (FSS) located in the southern part of Poland and the other (FSN) in the northern part, belonged to the National Fire Service and were staffed by career firefighters. The atmospheric air quality between the location sites differ greatly [32]. At each fire station, five four-hour long air sample-takings were performed in March and April 2018. Each taking of a sample started in the morning at shift change, when one crew was leaving and the next crew was taking their gear from the changing room. A single taking of a sample consisted of drawing air at $2000 \mathrm{cc} / \mathrm{min}$ through sorption tubes filled with Amberlite XAD2 (SKC) resin using 3 GilAir ${ }^{\circledR}$ Plus Personal Air Sampling Pumps (Sensidyne, USA) simultaneously in the changing (locker) room, garage, and outside the building. In each garage the watch room was located where firefighters were on duty $24 \mathrm{~h}$ a day. Neither the garages nor changing rooms were equipped with air conditioning; they had gravitational ventilation. At both stations, the entrance to the gym was from the changing room.

The PAHs adsorbed on the XAD-2 bed were extracted. Each tube (sample) was broken and the exposed XAD-2 was placed in a glass vial containing $5 \mathrm{ml}$ of acetonitrile $\left(\mathrm{CH}_{3} \mathrm{CN}\right.$, J.T.Baker ${ }^{\mathrm{TM}}$ ) and kept in an ultrasonic bath for 30 minutes. The extract was filtered through a membrane filter (PTFE, $45 \mu \mathrm{m}$ ) and the filtrate was concentrated in a nitrogen stream to $0.5 \mathrm{ml}$ (MultiVap, LabTech Co.). The PAH content of the concentrated extract was determined by means of high-performance liquid chromatography (HPLC) using a Surveyor Finningan chromatograph with a UV/Vis LC detector, PAH LC Column (ID 31105-254630), and ChromQuest software (each from Thermo Scientific). The mobile 
phase (acetonitrile aqueous solution 60:40 v/v) flow rate was $1.2 \mathrm{ml} / \mathrm{min}$, the wavelength used was $254 \mathrm{~nm}$.

The following $15 \mathrm{PAH}$ were determined: naphthalene $(\mathrm{Na})$, acenaphthene (Ace), fluorine (Fl), phenanthrene (Phe), anthracene (Ant), fluoranthene (F), pyrene (Py), benzo $[a]$ anthracene $(\mathrm{BaA}), \quad$ chrysene $(\mathrm{Ch})$, benzo[b]fluoranthene (BbF), benzo $[k]$ fluoranthene $(\mathrm{BkF})$, benzo $[a]$ pyrene $(\mathrm{BaP})$, indeno[1,2,3-c,d]pyrene (IcdP), dibenzo $[a, h]$ anthracene (DahA), benzo[ $g, h, i]$ perylene (BghiP). The calibration curve was plotted for each PAH separately using a standard mixture of 16 PAHs (610 PAH Calibration Mix A, RESTEK) containing each compound at a known concentration. The limit of detection for each PAH was $0.2 \mathrm{ng} / \mathrm{ml}$.

\section{Results and discussion}

The means and standard deviations of all five-element PAH concentration series are presented in Table 1. In Figure 1, the PAH profiles in the rooms and in the atmospheric air at each site are presented.

At both sites, the greatest average concentration of the sum of the 15 PAHs ( $\mathrm{PAH})$ occurred in the changing rooms. At FSN, the $\Sigma \mathrm{PAH}$ concentration was higher in the garage than outside; at FSS, the $\Sigma \mathrm{PAH}$ concentration was lower in the garage. The ambient air in the southern part of Poland is more polluted with PM-bound PAHs than the air in the northern part [32]. The values of the $\mathrm{P} A H$ concentrations from Table 1, two times greater at FSS than at FSN, may suggest that the situation with gaseous PAHs is similar, but such a generalization is not allowed as they result from a very short measuring session. Also, the variability of the measured concentrations (great standard deviations, Table 1) means the possibility of an occurrence of entirely different PAH concentrations at both sites during another measurment period. In Poland, ambient gaseous PAHs have not been investigated, thus there are no data for comparison for the results received in this study.

Table 1. Mean indoor (changing room, garage) and outdoor (atmospheric air) concentrations of gaseous PAHs $\left(\mathrm{ng} / \mathrm{m}^{3}\right)$ at two fire stations in Poland.

\begin{tabular}{lllllll}
\hline \multirow{2}{*}{ FSN } & \multicolumn{2}{l}{ Changing room } & Garage & \multicolumn{3}{l}{ Outdoor } \\
& Mean & St. dev. & Mean & St. dev. & Mean & St. dev. \\
\hline naphthalene (Na) & 3620 & 786 & 2764 & 1384 & 1084 & 1580 \\
acenaphthene (Ace) & 869 & 453 & 646 & 966 & 352 & 324 \\
fluorine (Fl) & 175 & 128 & 27 & 15 & 10 & 10 \\
phenanthrene (Phe) & 109 & 14 & 39 & 5 & 38 & 7 \\
anthracene (Ant) & 14 & 2 & 0 & 0 & 0 & 0 \\
chrysene (Ch) & 30 & 1 & 0 & 0 & 0 & 0 \\
fluoranthene (F) & 118 & 10 & 27 & 4 & 38 & 13 \\
pyrene (Py) & 49 & 7 & 16 & 2 & 4 & 7 \\
benzo[a]anthracene (BaA) & 17 & 2 & 0 & 0 & 0 & 0 \\
benzo[b]fluoranthene (BbF), & 19 & 2 & 0 & 0 & 0 & 0 \\
benzo[k]fluoranthene (BkF) & 10 & 1 & 0 & 0 & 0 & 0 \\
benzo[a]pyrene (BaP) & 3 & 6 & 1 & 2 & 3 & 5 \\
dibenzo[a,h]anthracene (DahA), & 6 & 6 & 1 & 2 & 11 & 19 \\
benzo[g,h,i]perylene (BghiP) & 0 & 0 & 0 & 0 & 0 & 0 \\
indeno[1,2,3-c, $d]$ pyrene (IcdP) & 10 & 8 & 0 & 0 & 0 & 0 \\
$\Sigma$ IPAH & 5047 & 1428 & 3522 & 2380 & 1540 & 1964 \\
\hline \multirow{2}{*}{ FSS } & Changing & room & Garage & & Outdoor & \\
& Mean & St. dev. & Mean & St. dev. & Mean & St. dev. \\
\hline naphthalene (Na) & 3327 & 624 & 1738 & 1151 & 2006 & 2206 \\
acenaphthene (Ace) & 1972 & 784 & 21 & 29 & 478 & 646
\end{tabular}


fluorine $(\mathrm{Fl})$

phenanthrene (Phe)

anthracene (Ant)

chrysene (Ch)

fluoranthene $(\mathrm{F})$

pyrene (Py)

benzo $[a]$ anthracene $(\mathrm{BaA})$

benzo[b]fluoranthene $(\mathrm{BbF})$,

benzo[ $k]$ fluoranthene $(\mathrm{BkF})$

benzo $[a]$ pyrene $(\mathrm{BaP})$

dibenzo $[a, h]$ anthracene (DahA), 2

benzo $[g, h, i]$ perylene (BghiP) 6

indeno $[1,2,3-c, d]$ pyrene (IcdP) 4

$\Sigma \mathrm{PAH}$

\begin{tabular}{llllll}
242 & 78 & 76 & 88 & 162 & 215 \\
129 & 128 & 83 & 106 & 147 & 167 \\
58 & 58 & 11 & 19 & 32 & 45 \\
25 & 22 & 10 & 18 & 11 & 19 \\
95 & 116 & 65 & 87 & 119 & 115 \\
52 & 46 & 33 & 31 & 13 & 23 \\
18 & 16 & 6 & 11 & 21 & 20 \\
7 & 12 & 5 & 8 & 0 & 0 \\
9 & 8 & 17 & 7 & 3 & 6 \\
2 & 4 & 0 & 0 & 3 & 5 \\
2 & 2 & 0 & 0 & 0 & 0 \\
6 & 10 & 0 & 0 & 0 & 0 \\
4 & 7 & 0 & 0 & 0 & 0 \\
5948 & 1915 & 2066 & 1556 & 2995 & 3468 \\
\hline
\end{tabular}

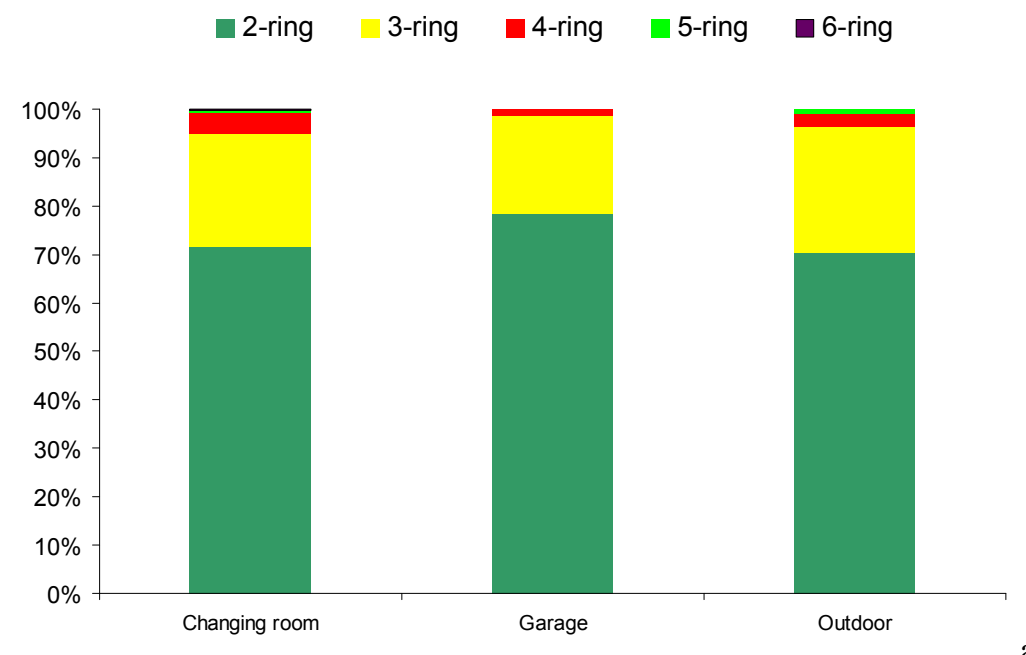

a)

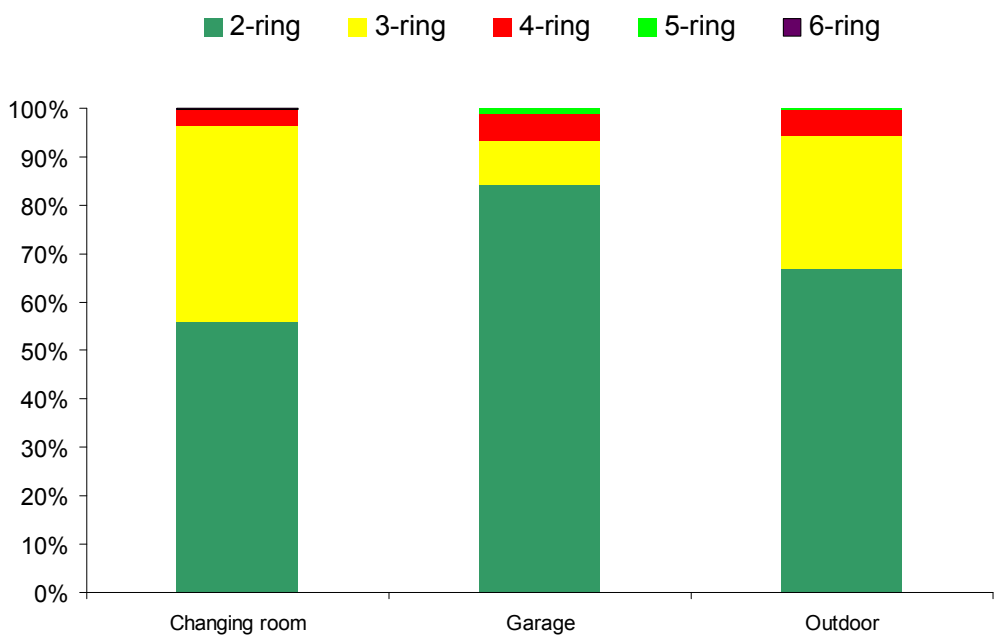

b)

Fig. 1. Mean profile of gaseous $\mathrm{PAH}$ in indoor (changing room, garage) and outdoor (atmospheric) air at two fire stations in Poland: FSN (a) and FSS (b). 
The standard deviations of the PAH concentrations in the changing rooms are relatively small compared to those for the garages and exterior, and their proportions to the means are also small (Table 1). They allow the belief that the gaseous PAH concentrations are always relatively high in both changing rooms. Almost all the measured PAHs occurred in the gaseous phase in the changing rooms while some heavier, 4-, 5-, and 6-ring ones, were not detectable in the atmospheric air.

At FSS, the majority of the PAHs had greater concentrations and more of them were detectable, both inside and outside. Therefore, the PAH profiles differ respectively pairwise between FSS and FSN; 3-, 4-, and 5-ring PAHs had greater shares in $\Sigma$ PAH at FSS than at FSN (Figure 2). Not surprisingly, the shares of 2-ring naphthalene and of all 3-ring PAHs dominated everywhere: 4-, 5-, and 6-ring PAHs occur in the air mainly as compounds bound to ambient particulate matter (PM-bound) [33], they contributed very little to the samples. However, being present in the air, they contribute to the health hazard and indicate the origins of PAH. To be able to adequately determine PAH origin, e.g. using diagnostic ratios (proportions of concentrations; DRs), and to have a comprehensive view of the health hazard from ambient PAHs in the fire stations, one should repeat the experiment and measure both gaseous and PM-bound PAHs. When only gaseous PAHs are measured, only the DRs computed from their concentrations are available, and here, three such DRs, $\mathrm{F} /(\mathrm{F}+\mathrm{Py}), \mathrm{BaA} /(\mathrm{BaA}+\mathrm{Ch})$, and $\mathrm{Ant} /(\mathrm{Ant}+\mathrm{Phe})$, were computed for each sampling site (Table 2). On the one hand they suffice to attribute the PAHs to the combustion of various materials and fuels proof exists that for both phases, gaseous and PM-bound, they are comparable, on the other hand $\mathrm{BaA} /(\mathrm{BaA}+\mathrm{Ch})$ can be 0.16 for gaseous PAHs and 0.33 for PM-bound PAHs [34-38].

Table 2. PAH diagnostic ratios for the the indoor and outdoor sampling points.

\begin{tabular}{llllllll}
\hline Diagnostic ratio & $\begin{array}{l}\text { FSN } \\
\text { Changing } \\
\text { room }\end{array}$ & Garage & Outdoor & $\begin{array}{l}\text { FSS } \\
\text { Changing } \\
\text { room }\end{array}$ & Garage & Outdoor & Source of PAH [33] \\
\hline An/(An+Fen) & 0.1 & 0.0 & 0.0 & 0.3 & 0.1 & 0.2 & $\begin{array}{l}>0,1 \text { - petrogenic } 0,24- \\
\text { coal burning } \\
<0,4 \text { - unburned }\end{array}$ \\
Flt/(Flt+Pyr) & 0.7 & 0.6 & 0.9 & 0.6 & 0.7 & 0.9 & $\begin{array}{l}\text { petroleum; } 0,57 \text { coal } \\
\text { burning; }>0,5 \text { coal, } \\
\text { grass, wood } \\
\text { BaA/(BaA+Ch) }\end{array}$ \\
\hline
\end{tabular}

The carcinogenic hazard from an ambient mixture of PAH can be expressed relative to the carcinogenicity of $\mathrm{BaP}$ as the $\mathrm{BaP}$ carcinogenicity equivalent (CEQ). $\mathrm{CEQ}$ is a linear combination of the ambient concentrations of PAHs from the mixture and their toxicity equivalency factors (TEFs) [39]. The CEQs computed for $\Sigma \mathrm{PAH}$ at FSS and FSN are presented in Figure 2. Although the outdoor $\Sigma \mathrm{PAH}$ concentration at FSS was two times greater than at FSN, the outdoor CEQ, i.e. the outdoor carcinogenic hazard from $\Sigma \mathrm{PAH}$, is greater at FSN. The CEQ for the FSN changing room is greater than that for the FSS one, and at both sites the CEQ for the changing room is the greatest among all three CEQs. For the garages, conversely, the CEQ for FSS is greater (Figure 2). All this situation is controlled by the ambient concentrations of benzo(a)pyrene and dibenzo(a,h)anthracene (Table 2), which have high TEFs [39], but their occurrence in a gaseous phase can be accidental here, since their distribution between gaseous and particulate phases depends on ambient air conditions [34-38]. 


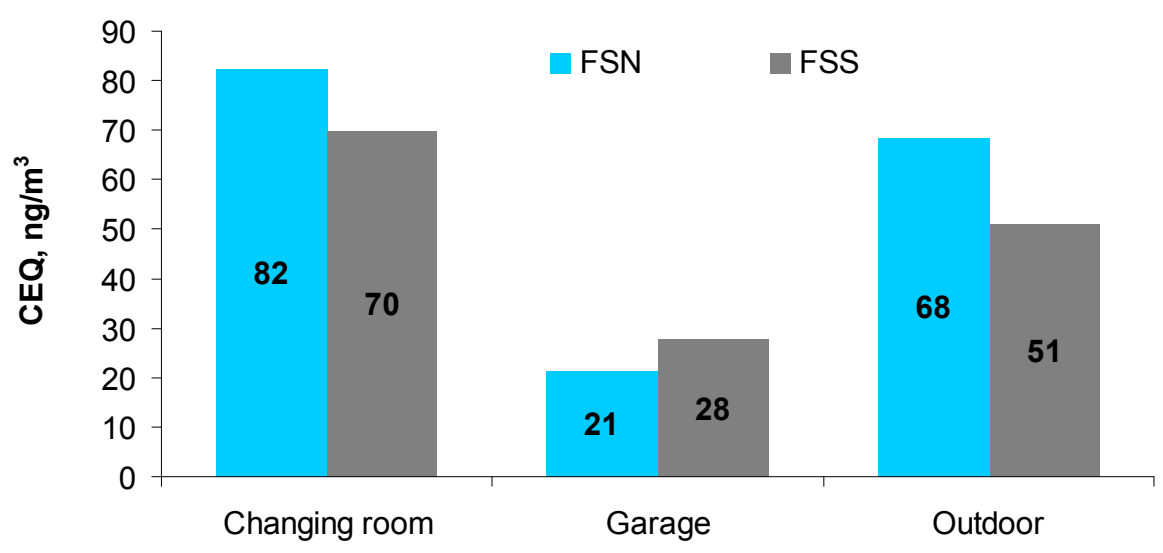

Fig. 2. Mean values of the $\mathrm{BaP}$ carcinogenicity equivalent for indoor and outdoor $\Sigma \mathrm{PAH}$ at fire stations in two Polish cities.

The firefighters' gear stored in the changing rooms after a firefighting action was the source of indoor PAHs. The firefighters' tournout clothes are washed using special chemicals in special laundries once or twice a month, therefore amajority of the contaminants are removed, but the level of gaseous PAHs in the changing room was still higher than outdoors. Firefighters usually stay in garages and changing rooms for short time, but we can suppose that PAHs from the garage and changing room can pass to adjacent or even further spaces, where people are resting, sleeping, or on duty for $24 \mathrm{~h}$ a day (as it is at the alarming posts in the garages).

\section{Conclusions}

The greatest concentrations of ambient PAHs, greater than in the garages or exterior of fire stations, occurred in the changing rooms where firefighter gear is stored after firefighting. Among the determined 15 PAHs, semivolatile naphthalene and acenaphthene had the greatest concentrations. According to the diagnostic ratios, the combustion of various materials and fuels was the PAH source at each site.

The conclusions from the investigations are following:

- Some PAHs contaminate firefighter gear during firefighting and are off-gassed while the gear is stored in a changing room. Decontamination of the firefighters' turnout gear after each action should decrease the indoor PAH levels at fire stations.

- Firefighter gear should be stored and handled in well-ventilated rooms. No turnout gear should be allowed in dormitories, gyms, kitchens, etc.

- To determine the actual risk from PAHs in firefighter stations, such measurements as presented here should be carried out in a more extensive form. The concentrations of gaseous and PM-bound PAHs should be measured in all fire station spaces where the crew spend their time, and perhaps in all seasons of the year.

The work was realized within the statutory research co-financed by funds of the Ministry of Science and Higher Education transferred to the Faculty of Fire Safety Engineering of The Main School of Fire Service in 2018. 


\section{References}

1. K.J. Aronson, G.A. Tomlinson, L. Smith, Am. J. Ind. Med. 26, 89-101 (1994)

2. D. Baris, T.J. Garrity, J.L. Telles, E.F. Heineman, A. Olshan, S.H. Zahm, Am. J. Ind. Med. 39, 463-476 (2001)

3. J.J. Beaumont, G.S. Chu, J.R. Jones, M.B. Schenker, J.A. Singleton, L.G. Piantanida, M. Reiterman, Am. J. Ind. Med. 19, 357-372 (1991)

4. K.W. Fent, D.E. Evans, J. Couch, HETA 2008-0241-3113 (2010)

5. K.W. Fent, J. Eisenberg, J. Snawder, D. Sammons, J.D. Pleil, M.A. Stiegel, C. Mueller, G.P. Horn, J. Dalton, Ann. Occup. Hyg. 58, 830-845 (2014)

6. W.J. Laitinen, M. Makela, J. Mikkola, I. Huttu, Toxicol. Lett. 192, 61-65 (2009)

7. W.J. Laitinen, M. Makela, J. Mikkola, I. Huttu Toxicol. Lett. 213, 129-133 (2012)

8. B. Ouyang, C.S. Baxter, H.M. Lam, S. Yeramaneni, L. Levin, E. Haynes, S.M. Ho, J. Occup. Environ. Med. 54, 774-80 (2012)

9. K.M. Kirk, M.B. Logan, J. Occup. Environ. Hyg. 12, 227-234 (2015)

10. M. Oliveira, K. Slezakova, M.J. Alves, A. Fernandes, J.P. Teixeira, C. Delerue-Matos, M.D.C. Pereira, S. Morais, Int. J. Hyg. Environ. Health. 219, 857-866 (2016)

11. P.M. Fine, G.R. Cass, B.R.T. Simoneit, Environ. Sci. Technol. 35, 2665-2675 (2001)

12. M.Kathleen Navarro, R. Cisneros, E.M. Noth, J.R. Balmes, S.K. Hammond, Environ. Sci. Technol. 51, 6461-6469 (2017)

13. S. Fernando, L. Shaw, D. Shaw, M. Gallea, L. VandenEnden, R. House, D.K. Verma, P. Britz-McKibbin, B.E. McCarry, Environ. Sci. Technol. 50, 1536-1543 (2016)

14. J.L.A. Keir, U.S. Akhtar, D.M. J. Matschke, T.L. Kirkham, H. Man Chan, P. Ayotte, P.A. White, J.M. Blais, Environ. Sci. Technol, 51, 12745-12755 (2017)

15. C.S. Baxter, J.D. Hoffman, M.J. Knipp, T. Reponen, E.N. Haynes. J. Occup. Environ. Hyg. 11, D85-91 (2014)

16. WHO, IARC, Monographs on the evaluation of the carcinogenic risks to humans: naphthalene, 82 (2002)

17. WHO, IARC, Monographs on the evaluation of the carcinogenic risks to humans: some non-heterocyclic polycyclic aromatic hydrocarbons and some related exposures, 92 (2010)

18. https://www.cdc.gov/niosh/firefighters/injury.html

19. P.A. Demers, H. Checkoway, T.L. Vaughan, N.S. Weiss, N.J. Heyer, L. Rosenstock, Cancer Causes Control. 5, 129-135 (1994)

20. C.A. Burnett, W.E. Halperin, N.R. Lalich, J.P. Sestito, Am. J. Ind. Med. 26, 831-833 (1994)

21. R.D. Daniels, S. Bertke, M.M. Dahm, J.H. Yiin, T.L. Kubale, T.R. Hales, D. Baris, S.H. Zahm, J.J. Beaumont, K.M. Waters, L.E. Pinkerton, Occup. Environ. Med. 72, 699-706 (2015)

22. R.D. Daniels, T.L. Kubale, J.H. Yiin, M.M. Dahm, T.R. Hales, D. Baris, S.H. Zahm, J.J. Beaumont, K.M. Waters, L.E. Pinkerton, Occup. Environ. Med. 71, 388-397 (2014)

23. E. Pukkala, J.I. Martinsen, E. Weiderpass, K. Kjaerheim, E. Lynge, L.Tryggvadottir, P. Sparen, P.A. Demers, Occup. Environ. Med., 71, 398-404 (2014) 
24. R.D. Daniels, T.L. Kubale, J.H. Yiin, M.M. Dahm, T.R. Hales, D. Baris, S.H. Zahm, J.J. Beaumont, K.M. Waters, L.E. Pinkerton, Occup Environ Med. 71, 388-397 (2014)

25. R.J. Tsai, S.E. Luckhaupt, P. Schumacher, R.D. Cress, D.M. Deapen, G.M. Calvert, Am. J. Ind. Med. 58, 715-729 (2015)

26. K.M.Kirk, M.B. Logan, J. Occup. Environ. Hyg. 12, 376-383 (2015)

27. B.M. Alexander, C.S. Baxter, J. Occup. Environ. Hyg. 5, 43-48 (2014)

28. B.M. Alexander, C.S. Baxter, J. Occup. Environ. Hyg. 9, 148-155 (2016)

29. K.W. Fent, D.E. Evans, D.Booher, J.D.Pleil, M.A. Stiegel, G.P.Horn, J. Dalton, J. Occup. Environ. Hyg. 12, 404-414 (2015)

30. K.W. Fent, B. Alexander, J. Roberts, S. Robertson, C. Toennis, D. Sammons, S. Bertke, S. Kerber, D. Smith, G. Horn, J. Occup. Environ. Hyg. 14, 801-814 (2017)

31. F.T. Borgerson J. Kerber, P. Gandhi, C. Baxter, C. Ross, J. Lockey, Firefighters exposure to smoke particulates - final report (2010)

32. W. Rogula-Kozłowska, K. Klejnowski, P. Rogula-Kopiec, L. Ośródka, E. Krajny, B. Błaszczak, B. Mathews, Air Qual. Atmos. Health. 7, 41-58 (2014)

33. W. Rogula-Kozłowska [In] Synergic Influence of Gaseous, Particulate, and Biological Pollutants on Human Health (ed. Jozef. S. Pastuszka), 68-108 (2015)

34. I.G. Kavouras, E.G.Stephanou, Indoor Air 12, 17-32 (2002)

35. D. Contini, A.Gambaro, F.Belosi, S. De Pieri, W.R.L.Cairns, A. Donateo, E. Zanotto, M. Citron, J. Environ. Manag. 92, 2119-2129 (2011)

36. I.C. Lai, C.L. Lee, K.Y. Zeng, H.C. Huang,. J. Environ. Manag 92, 2029-2037 (2011)

37. A. Dvorská, G. Lammel, J. Klánová, Atmos. Environ. 45, 420-427 (2011)

38. F. Mirante, C. Alves, C. Pio, O. Pindado, R. Perez, M.A. Revuelta, B. Artiñano, Atmos. Res. 132-133, 345-361 (2013)

39. I.C.T. Nisbet, P.K. LaGoy, Reg. Tox. Pharm. 16, 290-300 (1992) 